\title{
SUCCESSFUL GASTRIC CANCER PREVENTION
}

\author{
Stamboliyska M., I. Kotzev, P. Kolova ${ }^{1}$ \\ Clinic of Gastroenterology, St. Marina University Hospital of Varna, \\ ${ }^{1}$ Clinic of General and Clinical Pathology, St. Marina University Hospital of Varna
}

\begin{abstract}
Recently, knowledge of gastric cancer risk factors and pathogenesis allows successful preventive strategy. A 61-year old female patient with upper dyspeptic syndrome as well as with multiple gastric polyposis of mixed adenomatous and hyperplastic nature, Helicobacter-pylori $(\mathrm{Hp})$ infection, atrophic gastritis and severe bile reflux was reported. She was followed-up by endoscopy with histology once a year for 11 years. According to the OLGA staging system, the patient was stratified in group 3 of high GC risk. Hp infection was proved by urease test and histology. A polypectomy of the cardial polyps was performed and pathomorphologically examined. A 10-day sequential therapy for $\mathrm{Hp-infection} \mathrm{eradication} \mathrm{was} \mathrm{administered.} \mathrm{Long-lasting}$ chemoprevention with folic acid, antioxidants and aspirin/esomeprazol was recommended. Triple polypectomy of six polyps of mixed nature was performed. The patient is still free of disease.
\end{abstract}

Key words: gastric polyposis, Helicobacter-pylori infection, endoscopy, histology, gastric cancer, chemoprevention

\section{INTRODUCTION}

Gastric cancer (GC) is a multistep and multifactorial disease $(6,8)$. Helicobacter-pylori $(\mathrm{Hp})$ infection is the most consistent and essential risk factor for $70-95 \%$ GC cases $(1,6,7)$. Hp infected patients with gastric atrophy and intestinal metaplasia have a significantly increased risk developing GC $(1,7,13)$. Other precancerous conditions include atrophic gastritis, intestinal metaplasia, adenoma, and bile reflux.

\section{CASE REPORT}

In 2001, a 61-year old female patient was diagnosed with upper dyspeptic syndrome consisting of abdominal pain, nausea, belching, and regurgitation. Endoscopy showed multiple gastric hyperplastic polyposis. Malignancy was suspected in some larger peduncle polyps in the cardia sized over $20 \mathrm{~mm}$. Severe bile reflux and atrophic body gastritis were established, too. Histologically, in the cardia there were larger polyps of mixed adenomatous and hyperplastic nature while the rest polyps were hyperplastic. Besides atrophic gastritis in the corpus along with intestinal metaplasia foci in the antrum due to bile reflux of gastritis origin were histologically verified. According to the Operative Link on Gastritis Assessment (OLGA) staging system, the patient was stratified in group 3 of high GC risk. In ad-

Address for correspondence

M. Stamboliyska, Clinic of Gastroenterology,

St. Marina University Hospital of Varna

e-mail: m.stamboliyska@abv.bg dition, Hp infection was proved by urease test and histology. A polypectomy of the cardial polyps was performed and pathomorphologically examined. A 10-day regime of sequential therapy for $\mathrm{Hp}$-infection eradication was administered including esomeprazol $(2 \times 40 \mathrm{mg})$ plus amoxicillin $(2 \times 1000 \mathrm{mg})$ for the first 5 days and esomeprazole $(2 \times 40$ $\mathrm{mg})$ plus clarithromycin $(2 \times 500 \mathrm{mg})$ plus tinidasole $(2 \mathrm{x}$ $500 \mathrm{mg}$ ) for the next 5 days. Sucralfate and proton pump inhibitor therapy in routine dosage was prescribed for bile reflux gastritis. Long-lasting chemoprevention with folic acid and antioxidants was recommended. The patient was followed-up endoscopically once a year for a period of 11 years. During this period, triple polypectomy of six polyps of mixed nature was performed (Fig. 1).

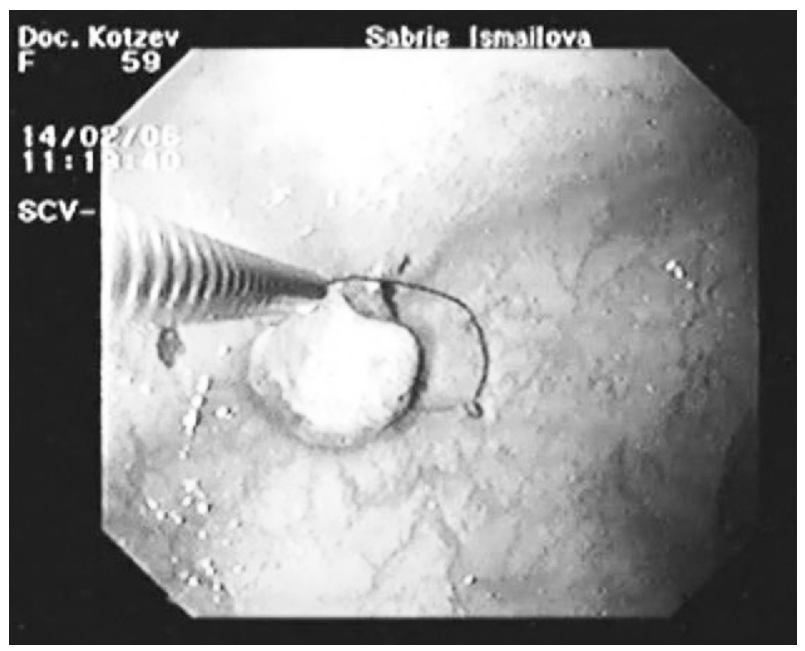

Fig. 1. Polypectomy of a polyp in the stomach body 
In one polyp, a hamartoma with dysplasia was histologically proved. Patient's monitoring still continues. Endoscopically, the number of the polyps did not change anymore. Histological examination shows hyperplastic polyps (Fig. 2).

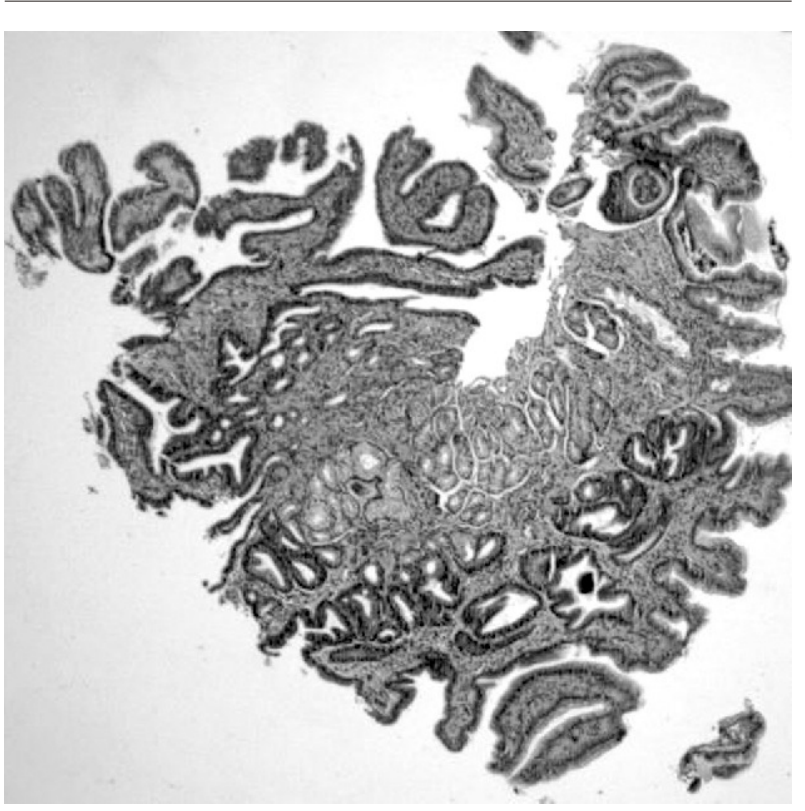

Fig. 2. A hyperplastic polyp with predominant foveal hyperplasia and non-abundant round-cell infiltration among the fibrous stoma. Staining with HE. Magn. $x$ 60,0

There is neither bile reflux, nor active gastritis. The inflammatory alterations have reduced. Hp-infection status is negative. There are no upper dyspeptic syndrome complaints anymore. Modern chemoprevention with aspirin and esomeprazol still continues for a long time.

\section{DISCUSSION}

Timely elimination of risk factors is essential in the prevention of GC (1,6-8). The clinical case reported above presents with a high risk for GC. In fact, there are some precancerous conditions such as atrophic gastritis, intestinal metaplasia, dysplasia, polyps with an adenomatous component, Hp infection, and bile reflux. The severe bile reflux is blamed for the development of intestinal metaplasia (9). Early identification and diagnosis of these conditions is a substantial part of their preventive strategy.

According to the Bulgarian consensus for GC, mass screening is performed only in subjects at risk for Hp infection as the most common proven risk factor for human non-cardial GC (15). In this respect, its elimination is the most promising strategy to reduce $\mathrm{GC}$ incidence rate $(2,6,8,10,14)$ and is a chance for gastric cancer prevention (7). Hp infection associated with atrophic gastritis is an absolute indication for eradication treatment, according to Maastricht III and Maastricht IV Concensus Reports $(6,8)$. This is effective in preventing GC when given before the occurrence of the aforementioned neoplastic conditions
$(6,8,17,18)$. It successfully abolishes the inflammatory response, slows or even stops the progression of atrophy (16). Endoscopic control with histological examination is the gold standard for screening and surveillance of gastric precanceroses $(17,18)$. Risk stratification of patients with premalignant gastric conditions is useful and should be based on the severity and distribution of lesions. According to OLGA staging system and Hp infection status, patients with gastritis can be stratified and managed according to their GC risk (11). Gastric adenomatous peduncle polyp should be polypectomized while broad-base polyps should be removed by endoscopic mucous resection. Subsequent behaviour is determined by the histological diagnosis, size and number of polyps (3).

In our case, endoscopic control, surveillance and triple polypectomy were properly done. Therefore, the combination of early diagnosis of gastric adenomatous polyposis, polypectomy, Hp eradication and significant risk factor removal represents an important integral part of GC prevention strategy (5). The regular administration of Aspirin and NSAIDs (1 tablet daily) for a long time (more than 5 years) reduces $\mathrm{GC}$ risk by $30-45 \%$ for distal GC but not for cardial GC (16). According to the AspECT (Aspirin and Esomeprazol Chemoprevention Trial), this therapy aims not only at preventing $\mathrm{GC}$ but also at decreasing the gastric side effects by combining aspirin with potent acid-suppressing drugs Aspirin could be the world's first proven GC chemopreventive agent (4).

\section{CONCLUSION}

Here we have reported a case of successful GC prevention. A contemporary prevention strategy by means of screening and surveillance of high risk individuals, risk factor removal in combination with early diagnosis of precanceroses and timely Hp eradication may be successful against GC.

\section{REFERENCES}

1. Asaka, M. Helicobacter pylori infection and gastric cancer.- Intern. Med., 41, 2002, No 1, 1-6.

2. Asaka, M., M. Kato, D. Y. Graham. Prevention of gastric cancer by Helicobacter pylori eradication.- Intern. Med., 49, 2010, No 7, 633-636.

3. Goddard, A. F., R. Badreldin, D. M. Pritchard, M. M. Walker, B. Warren; British Society of Gastroenterology. The management of gastric polyps.- Gut, 59, 2010, No 9, 1270-1276.

4. Jankowska, H., P. Hooper, J. A. Jankowski. Aspirin chemoprevention of gastrointestinal cancer in the next decade. A review of the evidence.- Pol. Arch. Med. Wewn., 120, 2010, No 10, 407-412.

5. Kotzev, I., M. Stamboliyska, I. Shalev, A. Lucheva, V. Glinkova, M. Mirchev, et al. Risk and protective factors for the development of gastric polyposis and cancer.- Savr. Med., 2007, No 2, 33-41 (in Bulgarian). 
6. Malfertheiner, P., F. Megraud, C. O'Morain, F. Bazzoli, E. E1-Omar, D. Graham, et al. Current concepts in the management of Helicobacter pylori infection: the Maastricht III Consensus Report.- Gut, 56, 2007, No 6, 772-871.

7. Malfertheiner, P., J. Bornschein, M. Selgrad. Role of Helicobacter pylori infection in gastric cancer pathogenesis: a chance for prevention.J. Dig. Dis., 11, 2010, No 1, 2-11.

8. Malfertheiner, P., F. Megraud, C. A. O'Morain, J. Atherton, A. T. Axon, F. Bazzoli, et a1.; European Helicobacter Study Group. Management of Helicobacter pylori infection the Maastricht IV/Florence Consensus Report.- Gut, 61, 2012, No 5, 646-664.

9. Park, M. J., K. H. Kim, H. Y. Kim, K. $\mathrm{Kim}$, J. Cheong. Bile acid induces expression of COX-2 through the homeodomain transcription factor CDX1 and orphan nuclear receptor SHP in human gastric cancer cells.- Carcinogenesis, 29, 2008, No 12, 2385-2393.

10. Peleteiro, B., C. La Vecchia, N. Lunet. The role of Helicobacter pylori infection in the web of gastric cancer causation.- Eur. J. Cancer Prev., 21, 2012, No 2, 118-125.

11. Rugge, M., J. G. Kim, V. Mahachai, S. Miehlke, G. Pennelli, V. M. Russo, et al. OLGA gastritis staging in young adults and country-specific gastric cancer risk.- Int. J. Surg. Pathol., 16, 2008, No 2, 150-154.

12. Selgrad, M., J. Bornschein, T. Rokkas, P. Malfertheiner. Clinical aspects of gastric cancer and Helicobacter pylori - screening, prevention, and treatment.- Helicobacter, 15, 2010, Suppl. 1, 40-45.

13. Uemura, N., S. Okamoto, S. Yamamoto, N. Matsumura, S. Yamaguchi, M. Yamakido, et al. Helicobacter pylori infection and the development of gastric cancer.- New Engl. J. Med., 345, 2001, No 11, 784-789.

14. Tulassay, Z., M. Stolte, L. Engstrand, E. Butruk, PP. Malfertheiner, P. Díté, et al.; HELIX Study Investigators. Twelve-month endoscopic and histological analysis following proton-pump inhibitor-based triple therapy in Helicobacter pylori-positive patients with gastric ulcers.- Scand. J. Gastroenterol., 45, 2010, No 9, $1048-1058$.

15. Vladimirov, B. Diagnostic and therapeutic algorithm (Consensus) of Bulgarian Scientific Unity of Gastroenterology.- Bulg. J. Hepatogastroenterol., 2010, No 2, 21-27 (in Bulgarian).

16. Yang, P., Y. Zhou, B. Chen, H. W. Wan, G. Q. Jia, H. L. Bai, et al. Aspirin use and the risk of gastric cancer: a meta-analysis.- Dig. Dis. Sci., 55, 2010, No 6, 1533-1539.

17. Yeh, J. M., C. Hur, K. M. Kuntz, M. Ezzati, S. J. Goldie. Cost-effectiveness of treatment and endoscopic surveillance of precancerous lesions to prevent gastric cancer.- Cancer, 116, 2010, No 12, 2941-2953.

18. Zullo, A., C. Hassan, A. Romiti, M. Giusto, C. Guerriero, R. Lorenzetti, et al. Follow-up of intestinal metaplasia in the stomach: when, how and why.- World J. Gastrointestin. Oncol., 4, 2012, No 3, 30-36. 